\title{
Conceptual Returns
}

\author{
Knut Christian Myhre \\ Museum of Cultural History, University of Oslo
}

I thank the editor for selecting my book for this inaugural journal feature, and the three reviewers for their serious and considered engagements with my text. It is an honour to receive such long reviews, especially from colleagues with expertise in areas that feature centrally for the book. It is moreover a rare privilege to be able to write back, even if I can only address some of the issues they raise.

In his rendition of the book's content and approach, Maximillian Chuhila attends to its concern with language, speech, and vernacular conceptualisations, and the topics and dynamics of life and dwelling, and their extensions and subversions. He queries how 'the individualised discourses and accounts' relate to broader social life in Rombo, and how this connects to the other Chagga-speaking areas in Kilimanjaro. Although the book's introduction locates Rombo in the region, and chapter one considers differential developments in modes of production and settlement in its different areas around the mountain, his point is fair that I do not continue a systematic comparison between them throughout the book. Still, a more implicit and non-systematic comparison occurs across both time and space through discussion of my contemporary ethnography in relation to the older descriptions and other historical source materials from elsewhere in Kilimanjaro.

However, Chuhila's question turns on an assumption or expectation that the analytical labour and achievement consist in connecting elements to larger or more encompassing units. There is nothing inherently wrong with such an ambition or undertaking, but it countervails the dynamic that I find to be at stake both in the social dynamic of Rombo and in Ludwig Wittgenstein's later philosophy. As the book shows, life and dwelling is less a question of connecting independently existing entities, and more a matter of ensuring the emergence of beings as the effects of life force and its movements through parts of other beings. Similarly, Wittgenstein's conception of language and meaning does not regard the integration of instances and element into larger systems, but the way language-games arise from 
and sink back into a form of life. Paraphrasing two forthcoming texts, both cases concern the becoming and being of relational composites, where each iteration involves and contains connections to other ones (Myhre 2019a; 2019b). It follows from this that the ethnographic material the book relies on is not 'individualised discourses and accounts', but events that can be mined for their intensive properties and recursive processes. As such, they resemble the situations and cases that Max Gluckman and his associates analysed in terms of patterns and transformations of relations, and that anticipated recent concerns with relations and their effects (Myhre 2013). Hence, Gluckman ([1961] 2005:21) advocated the disaggregation of 'gross concepts' into “...complex clusters of rights and duties, which operate with varying weight in different situations", and prophesied that, "We are, I believe, going into a much less tidy era of research, with concepts of society and structure and culture very much under critical examination". Sally Falk Moore points out that Gluckman influenced her processual approach, and it inspired my search for descriptive and conceptual tools of a finer grain than 'culture' and 'society'.

Indeed, I suspect that it is precisely such notions that underpin Chuhila's expectation that the significant relations obtain between Rombo and the other Chagga-speaking areas. Admittedly, these locations share linguistic and historical bonds, but as the proliferation of cognate notions throughout the region reveals, so does Rombo with other people in other places who speak other languages. In fact, the book's opening event manifests how those with whom I work orient towards and engage with Kamba-speaking people below the mountain. These relations were probably even closer and more significant in the colonial past, when young men herded cattle in the plains, attended mission schools in Taveta, and worked in Mombasa. These relations were overlaid during the economic hardship of the 1980s and 90s, when smuggling of sugar, kerosene, and other goods was rife across the border. The point is that the long-standing use of cognate languages entails that the entire region can be conceptualised as a gradient of similarities and difference that cuts across established analytics. Focusing on the uses of language and their imbrications with actions and objects thus provides a 
picture of higher resolution, and offers new lines of research that one can pursue around the mountain, but equally into other areas in the region.

The role and conception of language is the concern of Alex Pillen, who notes correctly that I do not cite the canon of linguistic anthropology. The simple reason is that the book is not intended as a contribution to that sub-discipline. It is therefore not incidental that I characterise this as a 'languageoriented ethnography'. Nevertheless, I share Pillen's wish that more transcripts and linguistic documentation could have been included. However, a book that was already long would then have failed to find a publisher and a readership. Yet, Pillen's claim that the book does not contain such material beyond the preface must mean she skipped significant parts of chapters two, four, and six, where similar invocations feature at length, albeit in translation.

A further reason for cutting back transcripts is the fact that language alone is not the book's subject matter. The focus is instead the composite language-games, and their potential for enriching our analytical vocabulary. As I describe the uses of vernacular notions with the aim of exploring their potential analytical use, I find bemusing Pillen's accusation of 'detached contemplation' and 'fetishization of language'. She hangs this on my rendering of vernaculars terms in brackets, yet also berates "...words roaming freely within the text", which "...may leave colleagues to experience linguistic vertigo". At once too much and not enough, Pillen chides my account for not meeting the requirements of analytical modes I never intended to address. By focusing on her own desires, she overlooks how the vernacular terms gradually deploy as descriptive tools that bend, stretch, or even displace our analytics. Thus, the notion of ialika modifies the concepts of bridewealth and marriage in terms of attachment and detachment, while idamira reworks mortuary ceremonies as related processes of emplacement and displacement. Through the act of description, the Chagga notions thus return as concepts capable of revising of our own. But Pillen does not address these concepts; instead, she relies on a detour through Germanic etymology and cosmology to make her criticism stick. She thus neglects how the uses of language and their practical and material concomitants modulate social 
relations, and how these employ as conceptual forms to modulate relations between our accounts and the languages we study. Such conceptual returns presuppose that language is not a raw material for them to use and for us to refine, but a common resource we all may use for different purposes. I therefore do not expect my interlocutors to share my descriptive interests, just as I do not expect my account to make rain in Kilimanjaro. Pillen is nevertheless right - the purpose is to liberate vernacular terms from their brackets and let them roam the text and the reader's mind, and perhaps reverberate in anthropology at large.

If the absence of linguistic anthropology troubles Pillen, so equally does the presence of Wittgenstein's philosophy. Yet how strange to restrict ourselves to linguistics and dismiss the philosophy of language, if our concern is the meaning and function of language. How odd, moreover, to reject someone who considers language integral to human practice and provides descriptive tools that open for ethnographic enquiry - not to mention that his work emerged from encountering anthropology. Veena Das reminds us that Wittgenstein's texts contain a multitude of voices that project from a plurality of positions with myriad affects and effects. His philosophy moreover focuses on language as an intersubjective means of communication, yet places no demands on the form those subjects must assume. It is thus highly amenable to a situation where both persons and speech are life force in particular forms, and language serves less to represent beings than project being into the world. Meanwhile, Pillen's sardonic claim that I personify the description rests on a certitude that subjects and speech are different in kind and character. However, Tony Crook (2007:218) argues that any ethnography amounts to a textual person, which bodies forth distinct relations that combine according to kinship-like constraints. By contrast, Pillen's position risks foreclosing what may occur and gain recognition in a material, and thus strikes me as un-ethnographic. We still need to heed Gluckman's ([1961] 2005:21) plead "...that anthropologists will have again to accustom themselves to welcoming great ethnographic detail". 
If my use of Wittgenstein is a step too far for Pillen, Veena Das asks if this engagement goes far enough. I share Das' concern that Wittgenstein is no ordinary philosopher, but one who deploys rhetorical and aphoristic forms as replacements for explicit and cumulative argumentation. I therefore regret if my account over-systematises or overdraws his ideas in the eagerness to explore the aspects most readily available for ethnographic exploration and anthropological analysis. In particular, I emphasise his equation of meaning and use to skirt relations of reference between words and objects that remain obstinate in anthropology, and instead grasp the multiple and diverse relationships that different language-games involve or gather up (see Myhre 2019b). My concern with their conceptual returns entails perhaps that I 'fall under the spell of anthropological theories'. However, it is also an effect of the ethnographic moment, which the use of Wittgenstein's ideas complicates beyond a mutual engagement of the field and the study (Strathern 1999). Since I deploy unfamiliar descriptive tools to explore ethnography beyond that of previous scholarship, other analytic terms must remain familiar. However, these modify in the process, which thus involves conceptual transfers and transformations that derive from vernacular concerns with linguistic and material conversions and conveyances. The account is therefore not theoretically overdetermined, but receives its orientation and movement from the ethnography.

Das points to areas of Wittgenstein's thought that I do not discuss, and questions whether and what I thereby miss. In particular, she queries the uncanny and the vulnerabilities of life, which in my view permeate Returning Life as inherent potentials to the transfers and transformations that dwelling and life entail. As Chuhila points out, the book can be read as two halves, which each concerns life and death, or fortune and misfortune. If it remains too much of a subtext, I point to my explorations of how witchcraft pertains to sociality and life, and the intrinsic possibilities of their negation (Myhre 2009; 2017). The way these turn on bodily interventions and mutilations gains a deeper sense from how initiation reconfigures the person and his or her capabilities through bodily modifications (Myhre 2019a). While these accounts do not discuss Wittgenstein, they draw inspiration from his thought to explore how the life affirming and the life denying inhere in each other in Kilimanjaro. 
I readily admit that my discussion of Wittgenstein's work neither is nor aims to be complete. I am moreover uncertain who speaks in the quote Das provides and which position it represents. A result of Wittgenstein's mode of writing is that one must always ask if it is a protagonist or antagonist who speaks, and to what effect. The situation is complicated by the fact that the physiognomy of words and aspect-seeing arguably rank among the least discussed and understood sections of his work. For instance, I recall a graduate seminar where only the last meeting on 'secondary sense' brought out widely diverging interpretations of his thought. Departing from the section: "Given the two concepts 'fat' and 'lean', would you be rather inclined to say that Wednesday was fat and Tuesday lean, or vice versa? (I incline decisively towards the latter.)" (Wittgenstein 1967:216, translation altered), our understandings ranged from straight-up metaphorical use to the contrasting appearances of 'Tuesday' and 'Wednesday' printed on the page. Like me, most commentators limit themselves to consider the first part of Philosophical Investigations and therefore do not provide a guide for reading such sections. The teacher of that seminar was one such commentator, but admitted to not having ever considered some of the interpretations the students launched that day. The recollection accentuates Das' point that there are many ways to read Wittgenstein's works, which all require persistence and effort.

A further point of complication is that Das cites scholars who explore Wittgenstein in conjunction with continental or American philosophy, while I draw on those who read him in connection with analytical philosophy. Wittgenstein's early work was crucial for the development of logical positivism and his later for ordinary language philosophy, but the latter furthermore straddles the analytical, continental, and American traditions. The depth and breadth of his thought mean it can yield concepts and relations beyond those I consider. Employed as tools of ethnographic description, they moreover afford an openness that allows for conceptual returns, where the vernacular may move the analytic beyond established confines. I do not discount that there are things I do not see, and therefore welcome the invitation for further engagement in the spirit of friendship. After all, the beauty and truth of ethnography is that it has no end yet is an end in itself, just like friendship and life itself. 


\section{References}

Crook, T. 2007. Exchanging Skin: Anthropological Knowledge, Secrecy and Bolivip, Papua New Guinea. Oxford: Oxford University Press.

Gluckman, M. [1961] 2005. Ethnographic Data in British Social Anthropology. Pp. 14-22 in The Manchester School: Practice and Ethnographic Praxis in Anthropology, eds. T.M.S. Evens and D. Handelman. Oxford: Berghahn.

Myhre, K.C. 2009. Disease and disruption: Chagga witchcraft and relational fragility. Pp. 118-140 in Dealing with uncertainty in contemporary African lives, eds. L. Haram and C. Bawa Yamba. Uppsala: Nordic Africa Institute.

Myhre, K.C. (2013). Cutting and Connecting: 'Afrinesian' perspectives on networks, exchange and relationality. Social Analysis 57, no. 3: 1-24.

Myhre, K.C. (2017). The Power of a Severed Arm: Life, Witchcraft, and Christianity in Kilimanjaro. Pp. 163-187 in Pentecostalism and witchcraft in Melanesia and Africa, eds. K. Rio, M. MacCarthy and R. Blanes. London: Palgrave.

Myhre, K.C. (2019a). Tales of a Stitched Anus: Fictions, Analytics, and Personhood in Kilimanjaro. Journal of the Royal Anthropological Institute 25(1).

Myhre, K.C. (2019b). Deep Pragmatism. In The Mythology in our Language: Remarks on Frazer's Golden Bough, ed. S. Palmié. Chicago: HAU Books.

Strathern, M. (1999). Property, Substance, Effect: Anthropological Essays on Persons and Things. London: Athlone Press.

Wittgenstein, L. 1967. Philosophical Investigations. Oxford: Blackwell. 